\title{
A soluble endoplasmic reticulum factor as regenerative therapy for Wolfram syndrome
}

\author{
Jana Mahadevan ${ }^{1} \cdot$ Shuntaro Morikawa $\mathbb{1}^{1} \cdot$ Takuya Yagi $^{1} \cdot$ Damien Abreu ${ }^{1} \cdot \operatorname{Simin} \mathrm{Lu}^{1} \cdot \mathrm{Kohsuke} \mathrm{Kanekura}^{1,2} \cdot$ \\ Cris M. Brown ${ }^{1} \cdot$ Fumihiko Urano $\mathbb{1}^{1,3}$
}

Received: 25 August 2019 / Revised: 18 April 2020 / Accepted: 19 April 2020 / Published online: 4 May 2020

(c) The Author(s) 2020. This article is published with open access

\begin{abstract}
Endoplasmic reticulum (ER) stress-mediated cell death is an emerging target for human chronic disorders, including neurodegeneration and diabetes. However, there is currently no treatment for preventing ER stress-mediated cell death. Here, we show that mesencephalic astrocyte-derived neurotrophic factor (MANF), a neurotrophic factor secreted from ER stressed cells, prevents ER stress-mediated $\beta$ cell death and enhances $\beta$ cell proliferation in cell and mouse models of Wolfram syndrome, a prototype of ER disorders. Our results indicate that molecular pathways regulated by MANF are promising therapeutic targets for regenerative therapy of ER stress-related disorders, including diabetes, retinal degeneration, neurodegeneration, and Wolfram syndrome.
\end{abstract}

\section{Introduction}

Growing evidence indicates that endoplasmic reticulum (ER) stress plays a critical role in $\beta$ cell death in type 1 and type 2 diabetes, as well as in neurodegenerative disorders, including Parkinson's disease and amyotrophic lateral sclerosis [1-5]. Despite the underlying importance of ER stress in $\beta$ cell death, there is currently no diabetes treatment targeting the ER due to the complex nature of type 1 and type 2 diabetes. Our strategy for overcoming this challenge is to focus on a monogenic form of diabetes, Wolfram syndrome. Wolfram

These authors contributed equally: Jana Mahadevan, Shuntaro Morikawa

Supplementary information The online version of this article (https:// doi.org/10.1038/s41374-020-0436-1) contains supplementary material, which is available to authorized users.

$\square$ Fumihiko Urano

urano@wustl.edu

1 Department of Medicine, Division of Endocrinology, Metabolism, and Lipid Research, Washington University School of Medicine, St. Louis, MO 63110, USA

2 Department of Molecular Pathology, Tokyo Medical University, Tokyo, Japan

3 Department of Pathology and Immunology, Washington University School of Medicine, St. Louis, MO 63110, USA syndrome is a rare disease characterized by juvenile-onset diabetes mellitus, optic nerve atrophy, and neurodegeneration $[6,7]$. As this syndrome is caused by mutations in the WFSI gene which is involved in ER calcium homeostasis and ER stress-mediated cell death, it is ideal for testing potential new treatments targeting the ER [8-14].

Mesencephalic astrocyte-derived neurotrophic factor (MANF) is a trophic factor whose expression and secretion is enhanced by ER stress and ER calcium depletion [1518]. It has been demonstrated that MANF plays a critical role in the survival of ER stressed $\beta$ cells and neurons $[19,20]$, raising the possibility that MANF-based treatment can be beneficial for patients suffering from ER stressrelated disorders, including Wolfram syndrome. Here we show that MANF-based treatment prevents $\beta$ cell death and enhances $\beta$ cell proliferation in cell and mouse models of Wolfram syndrome. Our results indicate that molecular pathways regulated by MANF are promising drug targets for ER stress-related disorders, including $\beta$ cell death in diabetes and Wolfram syndrome.

\section{Materials and methods}

\section{Cell culture}

Manf knockout INS-1 832/13 cells and Wfs 1 knockout INS-1 832/13 cells were created in collaboration with the Genome 
Engineering and Induced Pluripotent Stem Cell (iPSC) Center at Washington University using CRISPR-Cas9 genome editing techniques. INS-1 832/13 cells in which $W f_{s} 1$ expression can be suppressed by doxycycline-inducible shRNA directed against $W f_{s} I$ (INS-1 DOX-shWfsl) were generated as described previously [9]. Briefly, INS-1 832/13 cells stably expressing pTetR were transduced with lentivirus expressing pTER(H1/tetO)-shWfs1. INS-1 DOX-shWfs 1 were cultured in $2 \mu \mathrm{g} / \mathrm{ml}$ doxycycline (MilliporeSigma, St. Louis, MO) for $48 \mathrm{~h}$ before isolation of protein and RNA, and glucose-stimulated insulin secretion (GSIS) assay. INS-1 832/13 cells stably overexpressing MANF (MANF-OE) were created by transducing INS-1 832/13 cells with lentivirus expressing human MANF. INS-1 832/13 cells were cultured in RPMI 1640 (Thermo Fisher Scientific, Waltham, MA) supplemented with $10 \%$ FBS (Thermo Fisher Scientific), $1 \mathrm{mM}$ sodium pyruvate (Thermo Fisher Scientific), $100 \mathrm{nM} \beta$-mercaptoethanol (MilliporeSigma), and penicillin-streptomycin (Thermo Fisher Scientific). Tetracycline-free FBS (Takara Bio USA, Mountain View, CA) was used for culturing INS-1 DOX-shWfs1.

\section{Animal experiments}

$W f s 1 \beta$ cell-specific knockout $\left(\beta W f_{s} I^{(-l-)}\right)$ mice were generated by breeding the Cre recombinase driven by rat insulin promoter (Rip2-Cre) transgenic mice (originally from Dr Pedro Herrera) with $W f_{s} 1$ floxed mice [21]. All animal experiments were performed according to procedures approved by the Institutional Animal Care and Use Committee at the Washington University School of Medicine (A-3381-01).

\section{Immunoblot analysis}

INS-1 832/13 cells were washed in cold PBS and lysed with M-PER reagent (Thermo Fisher Scientific) containing Complete $^{\mathrm{TM}}$ protease inhibitor cocktail (MilliporeSigma). The equivalent amounts of cell lysates were resolved by SDS-PAGE using 4-20\% Mini-PROTEAN ${ }^{\circledR}$ TGX $^{\text {TM }}$ Precast Protein Gels (Bio-Rad Laboratories, Hercules, CA) and blotted onto Immobilon-P PVDF membrane $(0.45 \mu \mathrm{m})$ (MilliporeSigma). The following primary antibodies were used for detecting the protein of interest; WFS1 antibody (Proteintech, Rosemont, IL), cleaved caspase-3, GAPDH, alpha-tubulin and beta-actin antibody (Cell Signaling Technology, Danvers, MA), and anti-MANF antibody (Abnova, Taipei City, Taiwan) at 1:1000 dilution. The secondary antibodies conjugated to horseradish peroxidase were obtained from Cell Signaling Technology. The detection was performed by enhanced chemiluminescenceselect (GE Healthcare Bio-Sciences, Pittsburgh, PA). Fiji/ ImageJ was used for the quantification of immunoblot.

\section{Quantitative PCR}

Total RNA was extracted from INS-1 832/13 cells using the RNeasy Mini Kit (Qiagen, Germantown, MD) and reverse transcribed using High-Capacity cDNA Reverse Transcription Kits (Thermo Fisher Scientific). The expression of Manf and ER stress-related genes including Binding immunoglobulin protein (Bip), CCAAT/enhancer-binding protein-homologous protein (Chop), spliced X-box binding protein (Xbp1) (sXbpl), and Tribbles Pseudokinase 3 (Trb3) were detected by quantitative PCR (qPCR) using SYBR green reagents (Bio-Rad Laboratories). The qPCR was performed in triplicate for each sample. The primers sequences were: rat Manf, 5'-TGAGGTATCGAAGC CTCTGG- $3^{\prime}$ and $5^{\prime}$-CTCGCAGATCTGGCTGTCTT-3'; rat actin, 5'-GCAAATGCTTCTAGGCGGAC- $3^{\prime}$ and $5^{\prime}$ AAGAAAGGGTGTAAAACGCAGC-3'; rat Bip, $5^{\prime}$-TGG GTACATTTGATCTGACTGGA- $3^{\prime}$ and $5^{\prime}$-CTCAAAGGT GACTTCAATCTGGG-3'; rat Chop, 5'-AGAGTGGTC AGTGCGCAGC- $3^{\prime}$ and $5^{\prime}$-CTCATTCTCCTGCTCCTTC TCC-3'; rat sXbpl, 5'-CTGAGTCCGAATCAGGTGC AG-3' and $5^{\prime}$-ATCCATGGGAAGATGTTCTGG-3'; rat Trb3 5'-ACCATGCGAGCCACATCTCTG- $3^{\prime}$ and $5^{\prime}$-CT AGCCATACAGCCCCACCTC- $3^{\prime}$.

\section{Primary islet culture}

Mouse primary islets were taken from $\beta W f s I^{(-l-)}$ mice. The mice were anesthetized, and pancreata were infused with $5 \mathrm{ml}$ of $0.45 \mathrm{mg} / \mathrm{ml}$ collagenase type $\mathrm{V}$ (MilliporeSigma) in Hank's balanced salt solution without $\mathrm{Ca}^{2+}$ (Thermo Fisher Scientific). After surgical removal, pancreata were incubated for $12 \mathrm{~min}$ at $37^{\circ} \mathrm{C}$, and then hand-shaken for $2 \mathrm{~min}$. Undigested acinar tissue was removed by using a $70-\mu \mathrm{m}$ cell strainer and recovered tissues were washed twice with ice-cold Hanks' balanced salt solution followed by centrifugation at $1100 \mathrm{rpm}$ for $1 \mathrm{~min}$. Islets were handpicked and preincubated in RPMI 1640 medium containing 10\% FBS and antibiotics before experimentation. Islets of equal size were handpicked to generate 3-5 technical replicates for all experiments. Very large and very small islets were excluded. The results were obtained from at least three independent experiments.

\section{Human islet culture}

Human islets were purchased from Prodo Laboratories (Aliso Viejo, CA), and cultured in CMRL-1066 medium (Corning Incorporated, Corning, NY) containing $5 \mathrm{mM}$ glucose, 100 units $/ \mathrm{ml}$ penicillin, $100 \mu \mathrm{g} / \mathrm{ml}$ streptomycin, $2 \mathrm{mM}$ GlutaMAX (Thermo Fisher Scientific), $250 \mu \mathrm{g} / \mathrm{ml}$ gentamycin (Thermo Fisher Scientific), $10 \mathrm{mM}$ HEPES (pH 7.4) (Thermo Fisher Scientific), and 10\% FBS. Human islets (30 islets/ well) were handpicked under a dissecting microscope. 
A

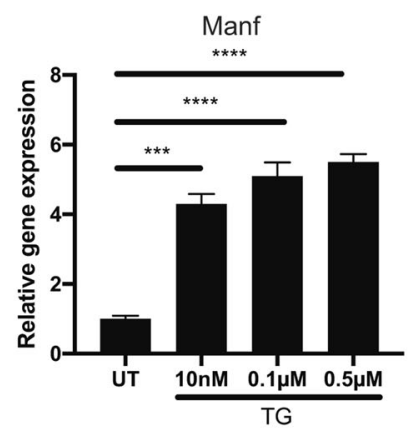

B

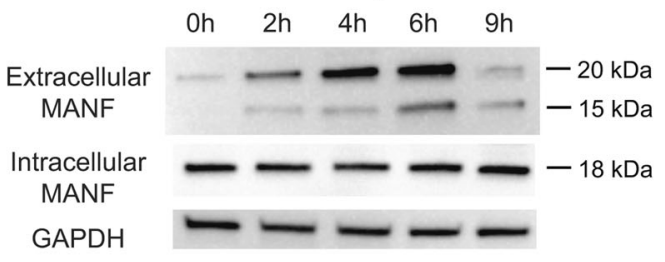

C
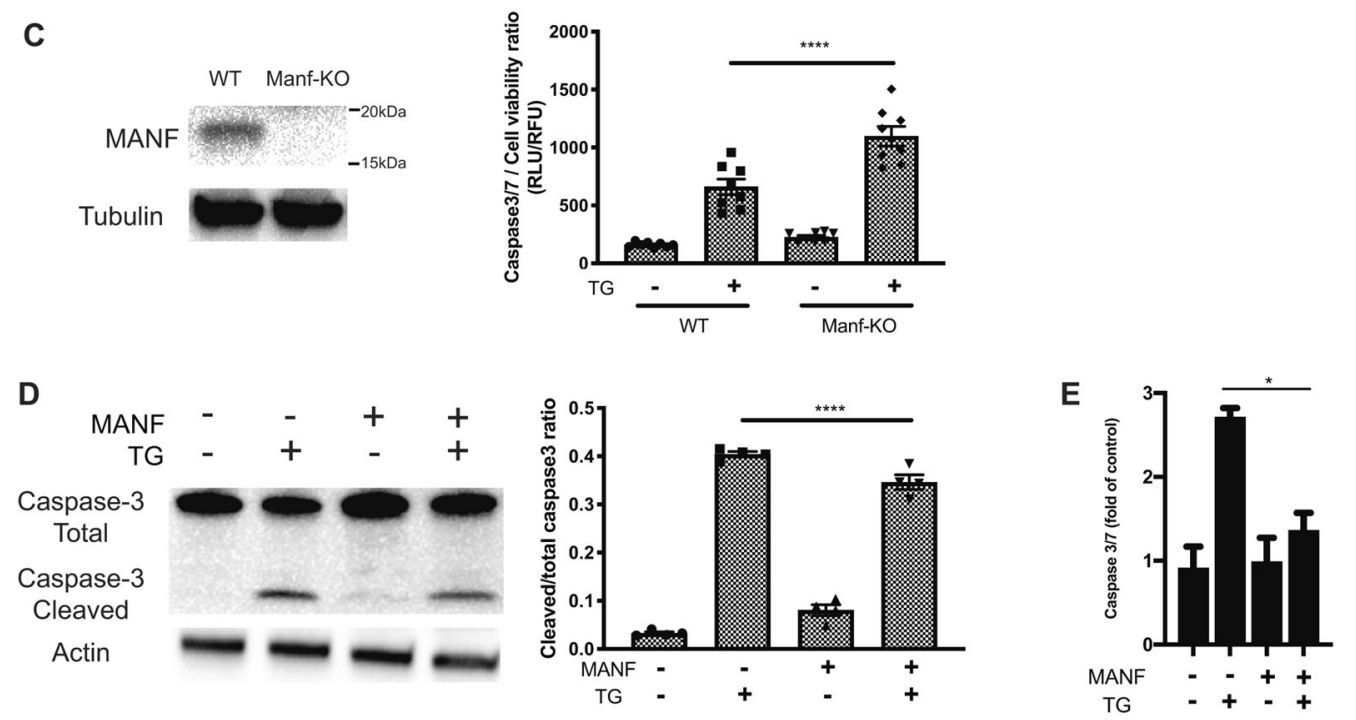

$\mathbf{F}$

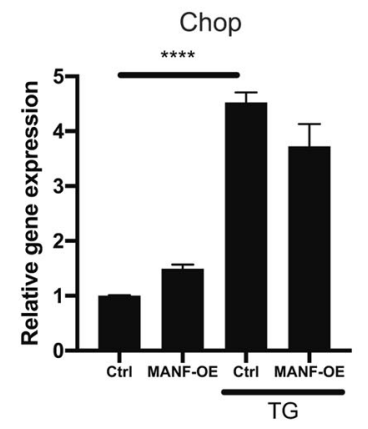

Trb3

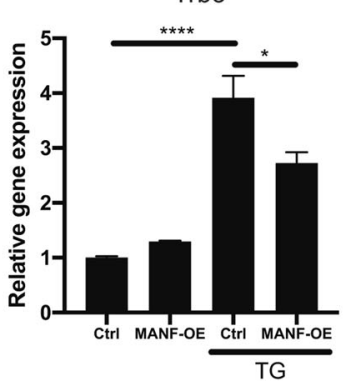

sXbp1

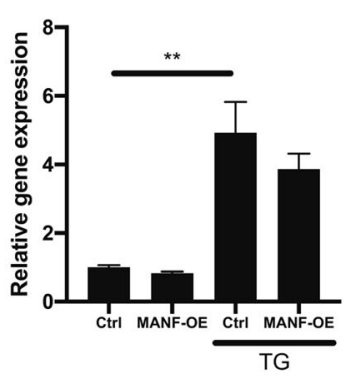

Bip

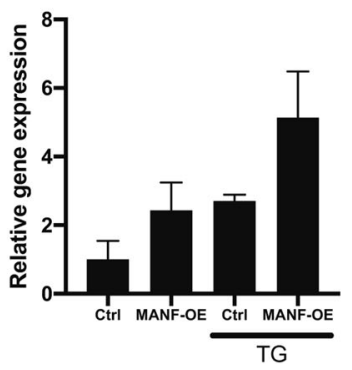

\section{Insulin secretion assay}

Primary mouse islets or INS-1 832/13 were cultured for $24 \mathrm{~h}$ and batches of ten islets were handpicked on the day of the experiment. Mouse islets or INS-1 832/13 were starved for $1 \mathrm{~h}$ in Krebs-Ringer bicarbonate-HEPES buffer $(129 \mathrm{mM}$

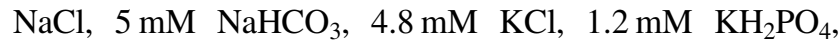
$1.2 \mathrm{mM} \mathrm{MgSO}_{4}, 10 \mathrm{mM}$ HEPES, and $1 \mathrm{mM} \mathrm{CaCl} 2$ at 
Fig. 1 MANF expression and secretion are induced by ER calcium depletion leading to suppression of ER stress-mediated cell death. a qPCR analysis monitoring Manf mRNA expression levels in INS-1 $832 / 13$ cells treated with thapsigargin (TG) $10 \mathrm{nM}$ for $24 \mathrm{~h}, 0.1 \mu \mathrm{M}$ or $0.5 \mu \mathrm{M}$ for $6 \mathrm{~h}$. UT untreated $(n=3, * * * P=0.0001, * * * * P<0.0001)$. b Western blot analysis monitoring extracellular and intracellular MANF levels. INS-1 832/13 cells were treated with $0.5 \mu \mathrm{M}$ of TG for indicated times. c Left panel: western blot for evaluating the expression level of MANF protein in wild type (WT) and Manf knockout (Manf-KO) INS-1 832/13 cells. Right panel: caspase-3/7 activity normalized to cell viability in INS-1 $832 / 13$ cells treated with or without TG $(0.1 \mu \mathrm{M}$ for $4 \mathrm{~h})(n=8, * * * * P<0.0001)$. d Western blot of cleaved caspase-3 in INS-1 832/13 cells pretreated with or without recombinant MANF peptide $(5 \mu \mathrm{g} / \mathrm{ml})$ for $24 \mathrm{~h}$, and then challenged with TG $(0.5 \mu \mathrm{M})$ for $6 \mathrm{~h}$. Quantification of immunoblot analysis is shown in the right panel $(n=4, * * * * P<0.0001)$. e The caspase- $3 / 7$ activity assay in INS-1 832/13 cells pretreated with recombinant MANF peptide $(5 \mu \mathrm{g} / \mathrm{ml})$ for $24 \mathrm{~h}$, and then challenged with TG $0.5 \mu \mathrm{M}$ for $6 \mathrm{~h}$. $\mathbf{f}$ Left panel: western blot for evaluating the expression level of MANF protein in control (Ctrl) and MANF overexpressed INS-1 832/13 (MANF-OE) whole cell lysate and supernatant. Right panel: qPCR analysis monitoring the expression levels of Chop, sXbp1, Trb3, and Bip mRNA in Ctrl and MANF-OE INS-1 832/13 cells challenged with TG $0.5 \mu \mathrm{M}$ for $6 \mathrm{~h}(n=3, * P<0.05$, $* * P<0.01$, $* * * * P<0.0001)$.

$\mathrm{pH}$ 7.4) containing $0.1 \%$ bovine serum albumin (KRBH/ BSA). KRBH/BSA was supplemented with $2.8 \mathrm{mM}$ glucose and then stimulated for $1 \mathrm{~h}$ at $37^{\circ} \mathrm{C}$ in $\mathrm{KRBH} / \mathrm{BSA}$ containing basal $5.5 \mathrm{mM}$ or stimulatory $16.7 \mathrm{mM}$ glucose. At the end of each incubation, supernatants were collected to measure insulin release, and cellular insulin contents were determined by acid-ethanol extraction followed by ELISA Rat/Mouse Insulin kit (MilliporeSigma).

\section{Cell proliferation}

The islets isolated from humans donor or $\beta W f s l^{(-)-)}$mice were dissociated by incubation with $0.25 \%$ trypsin-EDTA (Thermo Fisher Scientific) at $37^{\circ} \mathrm{C}$ for $5 \mathrm{~min}$ and treated with MANF peptide (R\&D Systems, Minneapolis, MN) 5 $\mu \mathrm{g} / \mathrm{ml}$ for 5 days. Two-thirds of the medium were changed daily to fresh medium with MANF peptide. To monitor the cell proliferation rate, the BrdU cell proliferation assay kit (Cell Signaling Technology) was used following the manufacturer's instruction.

\section{Caspase-3/7 activity in INS-1 832/13 cells}

INS-1 832/13 cells were cultured in RPMI medium in a 96well plate. Cells were treated with MANF peptide $(5 \mu \mathrm{g} / \mathrm{ml})$ for $24 \mathrm{~h}$, and then exposed to thapsigargin (MilliporeSigma). Caspase- 3 activity and cell viability were assessed using the Caspase-Glo ${ }^{\circledR} 3 / 7$ assay kit and the
CellTiter-Fluor ${ }^{\mathrm{TM}}$ cell viability Assay kit (Promega Corp., Madison, WI).

\section{Immunostaining}

Pancreatic tissue sections were fixed, rehydrated and permeabilized with $0.1 \%$ Triton $\mathrm{X}-100$ for $2 \mathrm{~min}$. The sections were washed with $0.1 \%$ Tween-20 PBS (PBS-T) containing Image-It FX signal enhancer (Thermo Fisher Scientific) for $1 \mathrm{~h}$ and incubated with primary antibodies overnight at $4{ }^{\circ} \mathrm{C}$ [guinea pig anti-insulin antibody (1:100, Thermo Fisher Scientific), MANF (1:100, Abnova), and Ki67 (1:100, Cell Signaling Technology)]. The tissue sections were washed three times in PBS-T and incubated with secondary antibodies for $1 \mathrm{~h}$ at room temperature. Images were obtained with a Zeiss LSM 5 PASCAL confocal microscope with LSM Image software.

\section{Measurement of $\beta$-cell mass}

For measurement of $\beta$-cell mass, every 40th pancreatic section was immunostained with guinea pig anti-insulin antibody (1:100, Thermo Fisher Scientific) and counterstained with hematoxylin. The $\beta$-cell mass for each mouse was quantified using Image Pro Plus software (Media Cybernetics, Rockville, MD) by obtaining the fraction of the cross-sectional area of pancreatic tissue (exocrine and endocrine) positive for insulin staining, and then multiplying this by the pancreatic weight.

\section{Measurement of apoptosis through TUNEL assay}

Apoptotic cells were detected using the terminal deoxynucleotidyl transferase dUTP nick end labeling (TUNEL) method as per the manufacturer's protocol (MilliporeSigma). For the determination of apoptosis, all $\beta$-cells per pancreatic sections (five sections per animal) were analyzed to count the total number of TUNEL-positive $\beta$ cells. An average of 150 islets was counted per animal and the percentage of TUNEL-positive cells was quantitated.

\section{In vivo administration of AAV vectors}

The methods for AAV production are described in Supplemental Information. AAV was produced in collaboration with the Hope Center Viral Vectors Core at Washington University. Male ( $n=3,2-3$ months of age) and female $\left(n=4,3-4\right.$ months of age) $\beta W f_{s} l^{(-/-)}$mice received intraperitoneal injections of AAV9-CBA-IRESGFP or AAV9-CBA-MANF-IRES-GFP at a final dose of $1 \times 10^{13}$ viral genome particles diluted in saline per 
A

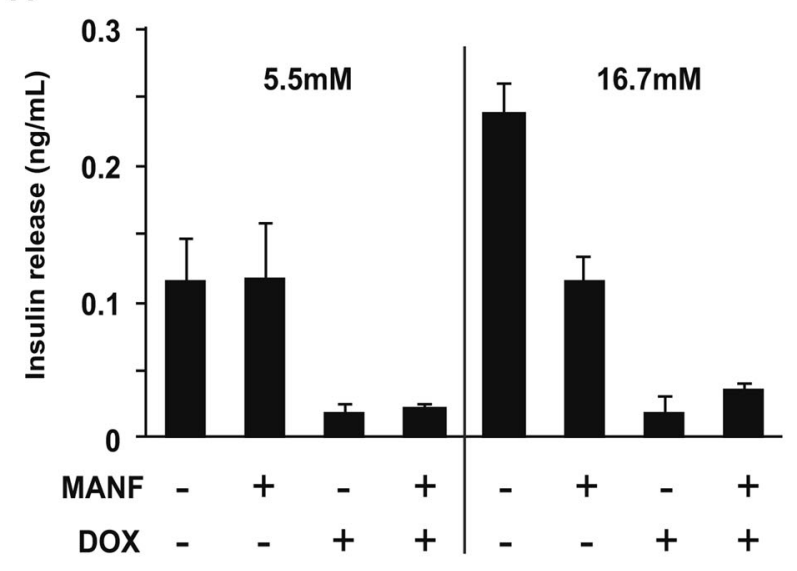

B

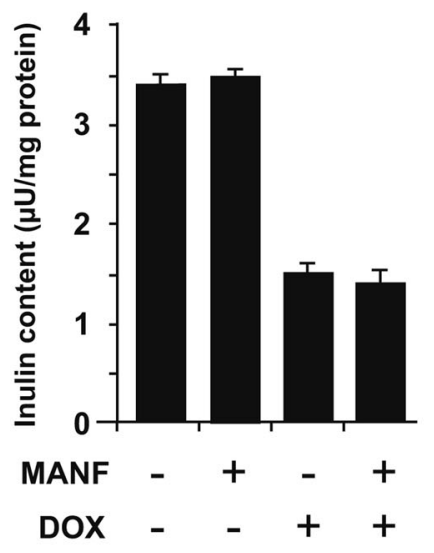

C

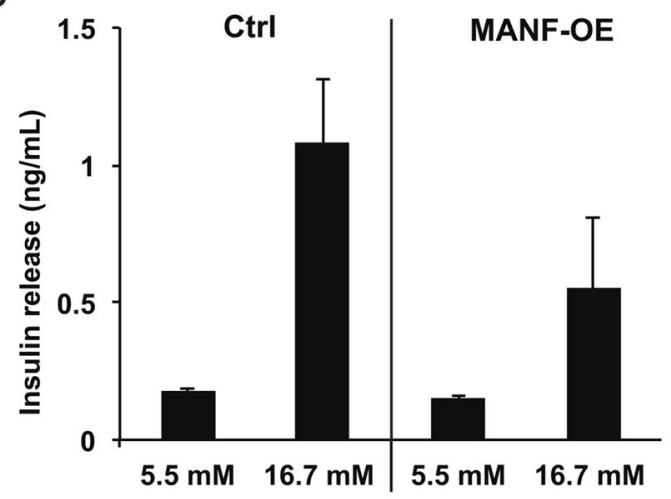

Fig. 2 Effect of MANF on glucose-stimulated insulin secretion. a Doxycycline-inducible shRNA directed against Wfs 1 (INS-1 DOX$\operatorname{sh} W f s 1)$ cells were treated with or without MANF peptide $(5 \mu \mathrm{g} / \mathrm{ml})$ for $24 \mathrm{~h}$, and then treated with doxycycline (DOX). Insulin release was measured at basal $(5.5 \mathrm{mM})$ glucose and stimulatory $(16.7 \mathrm{mM})$ glucose conditions ( $n=3$, not significant). b Cellular insulin contents were measured after the $24 \mathrm{~h}$ pretreatment with MANF peptide $(5 \mu \mathrm{g} / \mathrm{ml})$

mouse. After 4 weeks of AAV administration, the pancreata were harvested. Dissected pancreas pieces were fixed in $4 \%$ formalin. Formalin-fixed paraffin-embedded sections were deparaffinized and rehydrated. To estimate the $\beta$-cell replication rate, pancreatic sections were immunostained with anti-insulin and anti-Ki-67 antibody, a marker for cellular proliferation. Overall, 1500-3000 $\beta$ cells were counted in each animal.

\section{Data analysis}

The values are expressed as mean \pm SEM. All the statistical analysis was carried out with Prism 8 (ver 8.0.2). Comparisons among the group were done by Student's $t$ test. Multiple comparisons were performed by ANOVA followed by Tukey's test. $P<0.05$ was considered statistically significant.

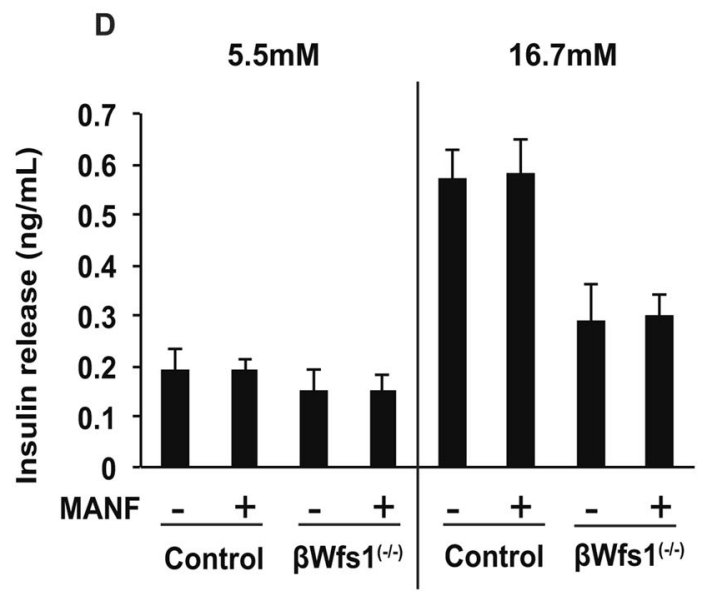

followed by DOX treatment ( $n=3$, not significant). $\mathbf{c}$ Glucose-stimulated insulin secretion on control (Ctrl) and MANF overexpressed INS-1 832/ 13 cells (MANF-OE). Insulin release was measured at 5.5 and $16.7 \mathrm{mM}$ glucose conditions ( $n=3$, not significant). d Primary islets isolated from wild type (WT) and $\beta$ cell-specific Wfs 1 knockout mice $\left(\beta W f s 1^{(-/-)}\right)$were pretreated with MANF peptide $(5 \mu \mathrm{g} / \mathrm{ml})$ for $24 \mathrm{~h}$. Insulin release was measured at $5.5 \mathrm{mM}$ and $16.7 \mathrm{mM}$ glucose $(n=3$, not significant).

\section{Results}

\section{MANF confers protection against cell death induced by ER calcium depletion}

We have recently shown that various $\beta$ cell perturbants, including the loss of function of Wolfram syndrome 1 (WFS1) gene, induce ER calcium depletion and ER stress, leading to $\beta$ cell death $[10,22]$. It has been recently reported that loss of MANF in vivo leads to $\beta$ cell death with ER stress elevation [20]. These considerations prompted us to monitor MANF expression levels in $\beta$ cells under stressed conditions. Although Manf mRNA expression was not changed by $W f s 1$ deficiency (Fig. S1), thapsigargin, which is a well-established ER calcium depletion inducer, increased Manf mRNA expression and MANF protein 
secretion in INS-1 832/13 cells (Fig. 1a, b). A smaller band of extracellular MANF corresponds to an isoform lacking RTDL domain which is prone to be secreted, and a larger band corresponds to an isoform containing RTDL domain which is glycosylated [15] (https://www.ncbi.nlm.nih.gov/ protein/NP_001101653.1,XP_006243837.1). Intracellular fraction only contains an isoform with the C-terminal RTDL domain [23]. While Manf knockout INS-1 832/13 cells were more sensitive to ER stress-induced cell death (Fig. 1c), recombinant MANF peptide pretreatment reduced cell death in INS-1 832/13 cells treated with thapsigargin (Fig. 1d, e). Furthermore, mRNA expression level of tribbles pseudokinase 3 ( $\operatorname{Tr} 33$ ), which is an ER stress-inducible gene, was significantly suppressed in INS-1 832/13 cells stably overexpressing MANF (MANF-OE) (Fig. 1f). Trb3 is a proapoptotic component of ER stress signaling [24-26], suggesting that MANF might suppress the proapoptotic arm of ER stress signaling in those models.

\section{Effect of MANF on insulin secretion}

Since the loss of MANF in vivo can lead to $\beta$ cell dysfunction, we studied the relationship between MANF and insulin secretion. We created INS-1 832/13 cells in which $W f s 1$ expression can be suppressed by doxycyclineinducible shRNA directed against Wfsl (INS-1 DOX$\operatorname{sh} W f s 1$ ) [9]. Glucose-stimulated insulin secretion (GSIS) assays were performed in INS-1 DOX-sh $W f_{s} 1$ cells, MANF-OE INS-1 832/13, and primary mouse islets isolated from $\beta$ cell-specific Wfsl knockout $\left(\beta W f s l^{(-/-)}\right)$mice treated with recombinant MANF peptide. As a consequence, MANF treatment or overexpression did not affect GSIS in those models (Fig. 2a-d).

\section{MANF activates proliferation of human primary islets}

The fact that the suppression of ER stress can lead to $\beta$ cell proliferation raised the possibility that MANF treatment might activate $\beta$ cell proliferation $[22,23]$. To test this idea, human primary islets were treated with recombinant MANF peptide and then their proliferation rates were assessed by the BrdU assay. Consequently, MANF treatment significantly induced the proliferation of human primary islets derived from two out of six donors (Fig. 3 and Supplementary Table).

\section{MANF-based treatment for Wolfram syndrome}

We have previously shown that ER calcium depletion, followed by ER stress-mediated cell death, plays a role in the pathogenesis of Wolfram syndrome [10, 22, 27], which prompted us to consider the possibility that MANF-based

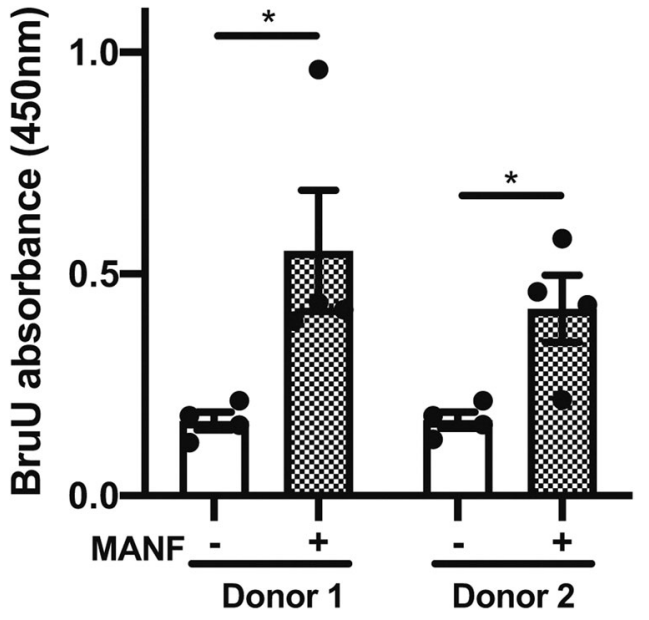

Fig. 3 MANF activates proliferation of $\boldsymbol{\beta}$ cells. The BrdU assay monitoring the proliferation of human primary islets treated with or without MANF peptide $(5 \mu \mathrm{g} / \mathrm{ml})$ for 5 days $(n=4, * P<0.05)$.

treatment could prevent $\beta$ cell death and activate $\beta$ cell proliferation in Wolfram syndrome. Cell death induced by $W f s 1$ knockdown in INS-1 DOX-shWfsl cells was prevented by recombinant MANF peptide treatment shown as cleaved caspase-3 protein and caspase-3/7 activity reduction (Fig. 4a, b). The proliferation of primary islets from $\beta W f s 1^{(-l-)}$ mice, which is a mouse model of Wolfram syndrome [21], was also enhanced by MANF treatment (Fig. 4c). Moreover, MANF treatment suppressed the expression of proapoptotic ER stress markers (Chop and Trb3) in INS-1 DOX-shWfsl cells (Fig. 4d) and MANF overexpression improved the viability of $W f s 1$ knockout INS-1 832/13 cells (Fig. S2).

Next, we analyzed the effect of MANF on $\beta$ cell proliferation in $\beta W f_{S} 1^{(-/-)}$mice. Adeno-associated virus 9 expressing MANF (AAV9-MANF) was injected intraperitoneally into $\beta W f s I^{(-l-)}$ mice. We then monitored $\beta$ cell proliferation for 5 weeks after the injections. Pancreas sections from those mice showed robust expression of MANF in islet $\beta$ cells, as well as in exocrine pancreatic cells (Fig. 5a). We found that $\beta$ cell proliferation rates in endocrine cells were higher in $\beta W f_{s} 1^{(--)}$mice injected with AAV9-MANF than in those injected with control AAV9 (Fig. 5b). $\beta$ cell mass was not increased in both groups (Fig. 5c). TUNEL-positive cells were rarely detectable in both groups $\left(\beta W f_{S} I^{(-1-)}\right.$ mice injected with AAV9-control, $0.09 \pm 0.02 \% ; \beta W f s 1^{(-l-)}$ mice injected with AAV9-MANF, $0.08 \pm 0.02 \%$ ) (Fig. 5a). Although MANF was also overexpressed in exocrine pancreatic cells, proliferation rates of these cells were comparable with control cells, suggesting that the proliferative effect of MANF might be specific for pancreatic $\beta$ cells (Fig. S3). Collectively, these results indicate that MANF enhances $\beta$ cell survival and proliferation in cell and mouse models of Wolfram syndrome. 

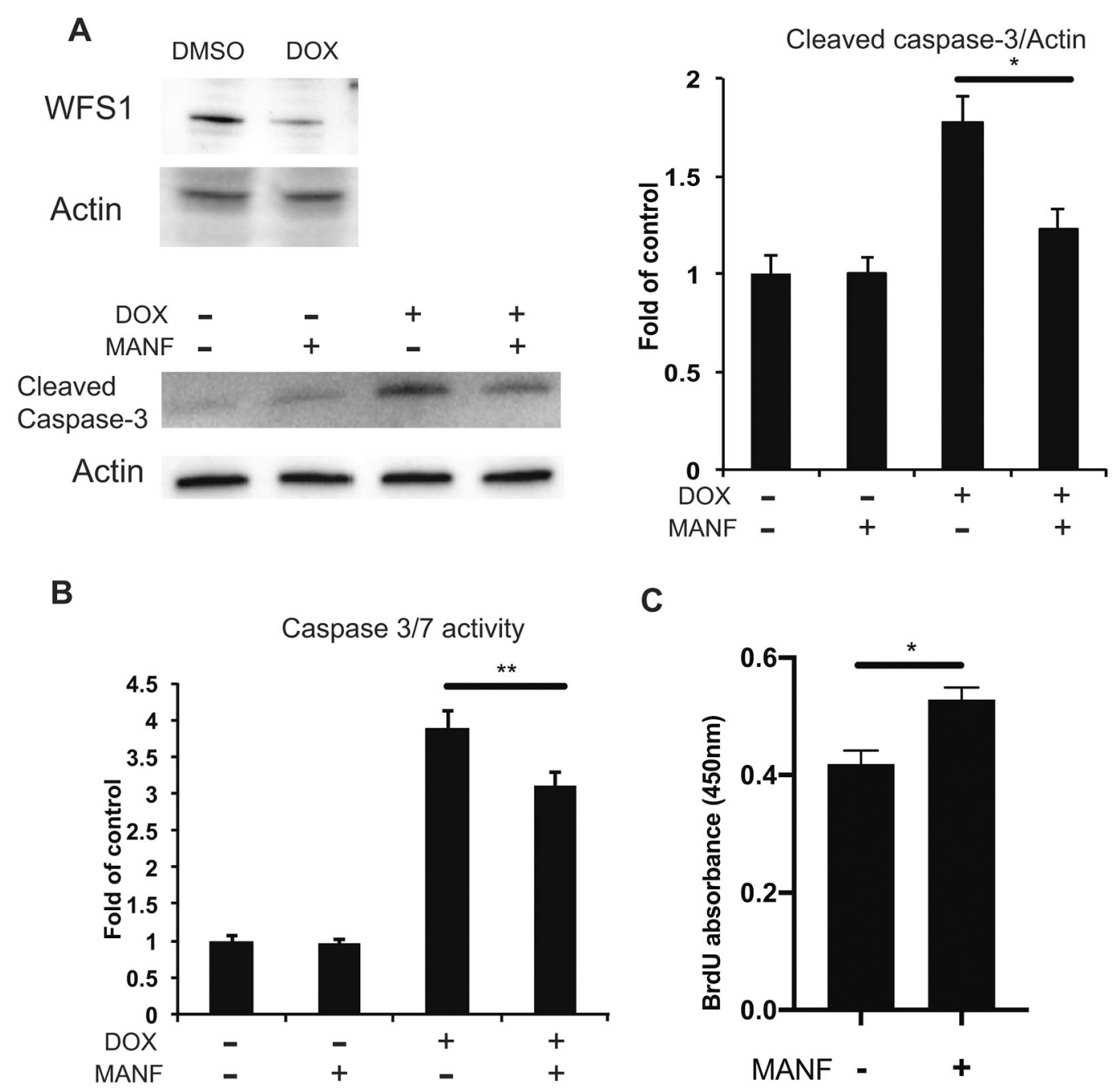

C
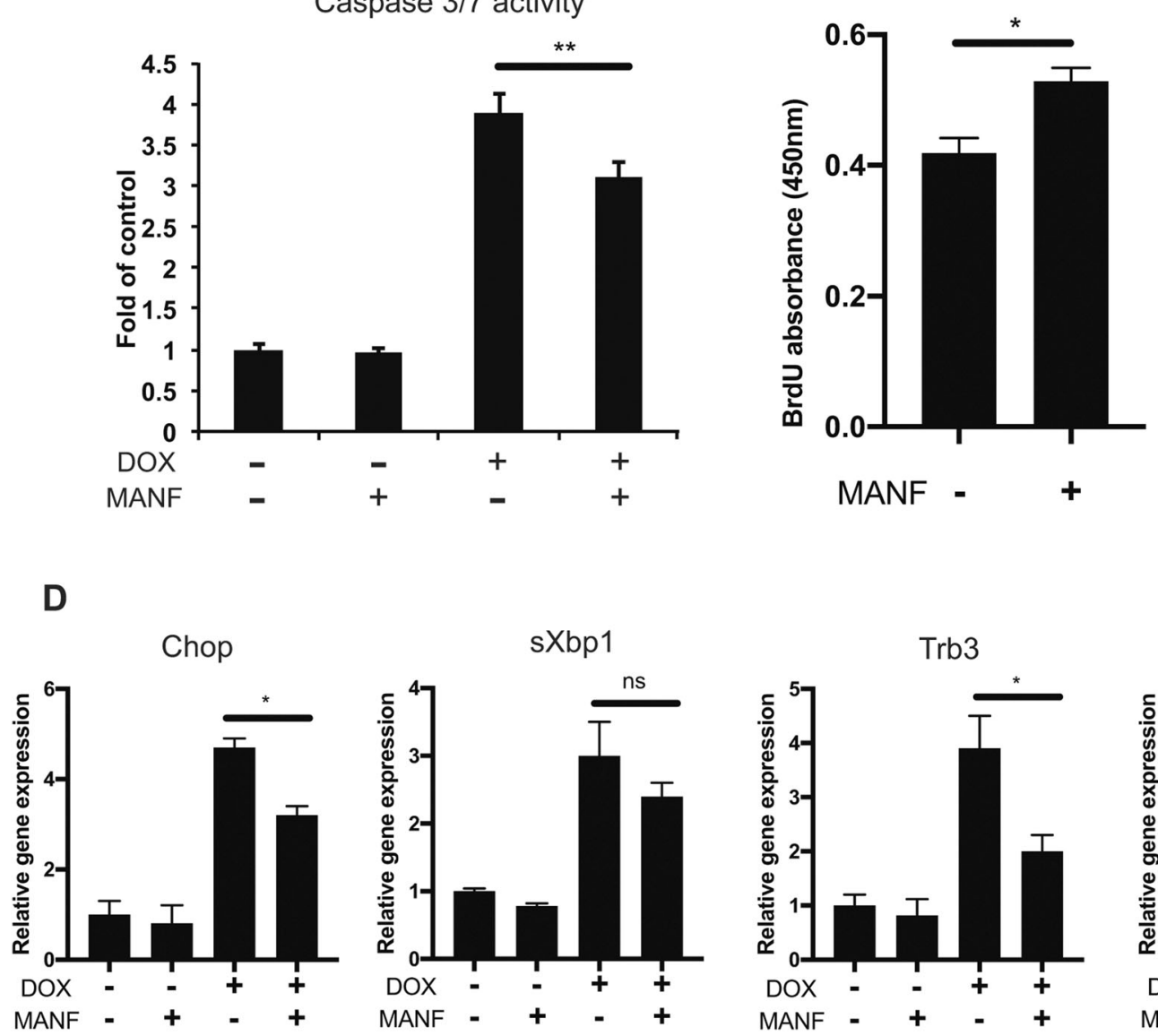

Fig. 4 MANF attenuates cell death and activates cell proliferation in $\boldsymbol{\beta}$ cell models of Wolfram syndrome. a Immunoblot analysis of cleaved caspase- 3 and actin in doxycycline-inducible shRNA directed against Wfs1 (INS-1 DOX-shWfs1) cells. INS-1 DOX-shWfs1 cells were untreated or pretreated with MANF peptide $(5 \mu \mathrm{g} / \mathrm{ml})$ for $24 \mathrm{~h}$, and then treated with doxycycline (DOX) for $W f_{s} 1$ suppression. The quantified ratio of cleaved caspase- 3 is shown in the right panel $(n=3$, $* P<0.05)$. b Caspase-3/7 activity assay in INS-1 DOX-sh $W f_{s} 1$ cells. INS-1 DOX-shWfs 1 cells were untreated or pretreated with MANF

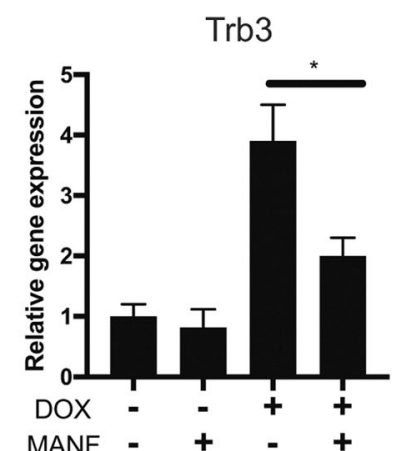

peptide $(5 \mu \mathrm{g} / \mathrm{ml})$ for $24 \mathrm{~h}$, and then treated with or without DOX for another $48 \mathrm{~h}(n=3, * * P<0.01)$. c BrdU assay of $\beta$ cell-specific $W f s 1$ knockout mice $\left(\beta W f_{s} I^{(-l-)}\right)$ primary islets. The isolated islets were treated with or without MANF peptide $(5 \mu \mathrm{g} / \mathrm{ml})$ for 5 days $(n=4$, $* P<0.05)$. $\mathbf{d}$ qPCR analysis monitoring the expression levels of Chop, $s X b p 1, T r b 3$, and Bip mRNA in INS-1 DOX-sh $W f s 1$ cells. The cells were treated with or without MANF peptide $(5 \mu \mathrm{g} / \mathrm{ml})$ for $24 \mathrm{~h}$, and then treated with $\operatorname{DOX}(n=3, * P<0.05)$. 
A
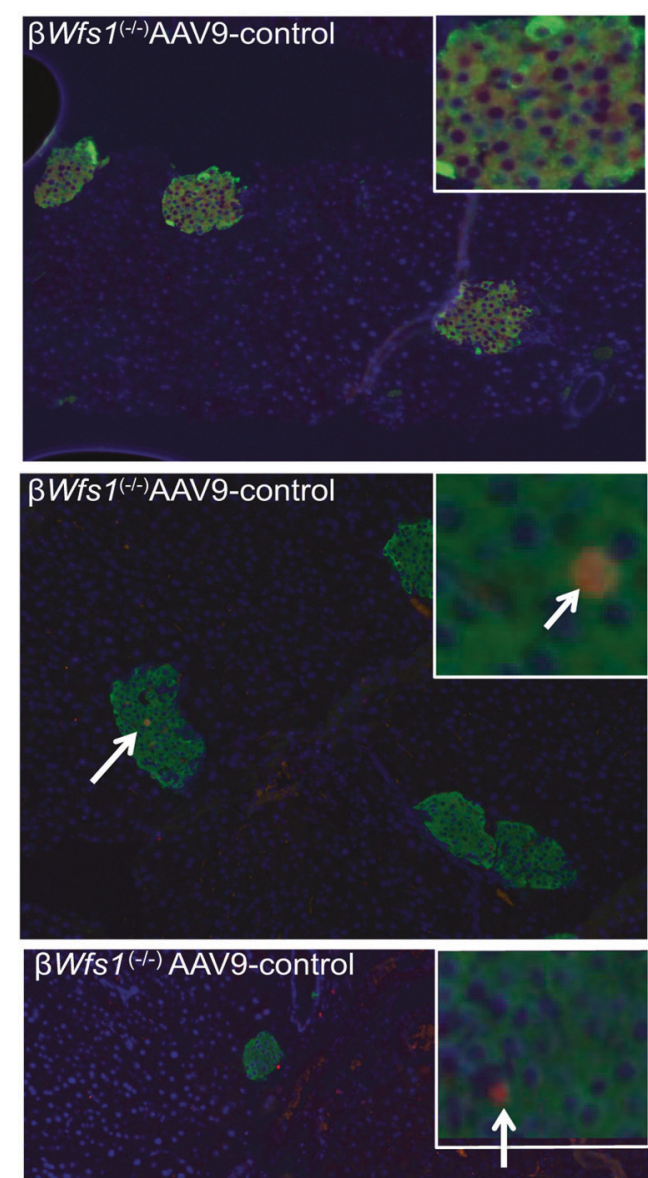

$\uparrow$

B

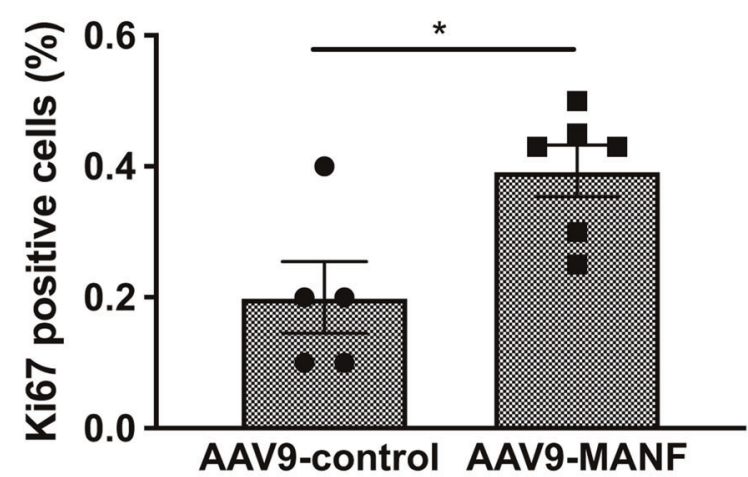

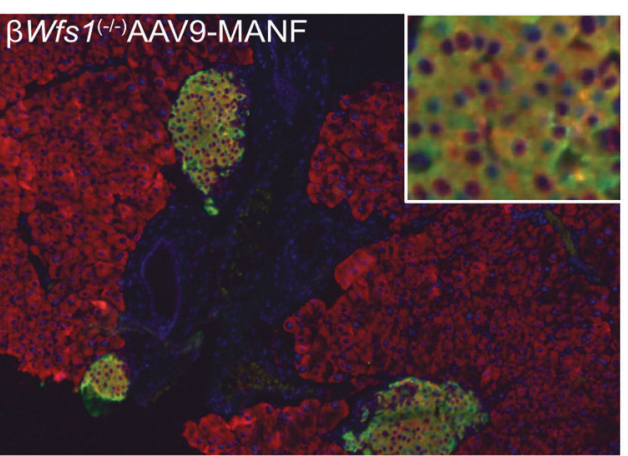

Green: Insulin

Red: MANF
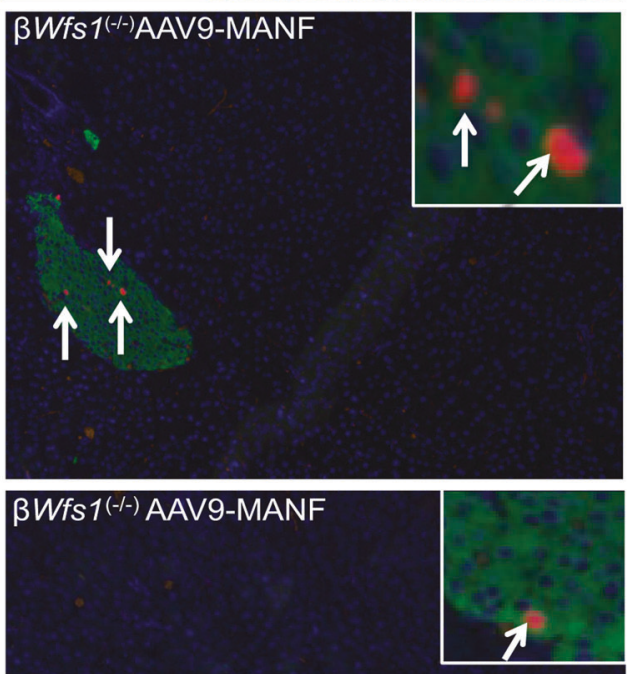

Green: Insulin

Red: TUNEL

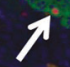

C

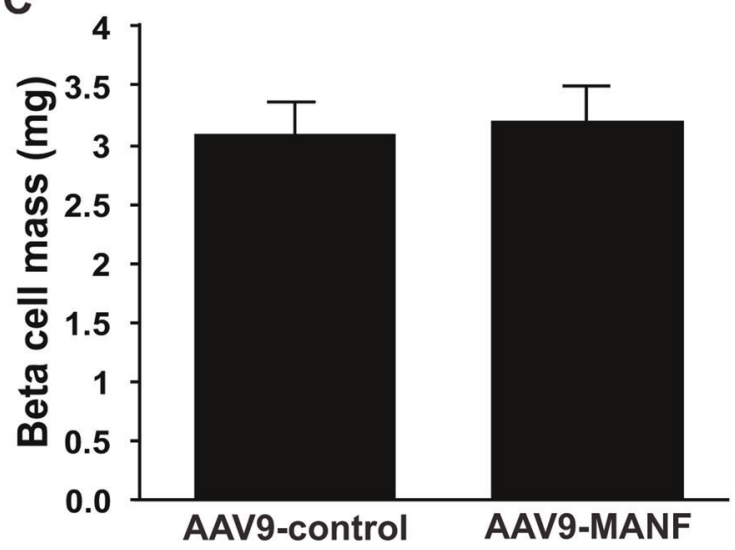


4 Fig. 5 Overexpression of MANF by AAV9 enhances $\beta$ cell proliferation in a mouse model of Wolfram syndrome. a Top panels: double immunofluorescence staining of insulin (green fluorescence) and MANF (red fluorescence) on pancreatic tissue sections from $\beta$ cell-specific $W f s 1$ knockout mice $\left(\beta W f s l^{(-l-)}\right)$ taken 5 weeks after intraperitoneal injection of AAV-control (AAV9-CBA-IRES-GFP) or AAV9-MANF (AAV9-CBA-MANF-IRES-GFP) vector $(n=6$ each group). Middle panels: double immunofluorescence staining of insulin (green fluorescence) and Ki67 (red fluorescence) of pancreatic sections from $\beta W f s 1^{(-/-)}$mice taken 5 weeks after intraperitoneal injection of AAV-control or AAV9-MANF vector ( $n=6$ in each group). Bottom panels: double immunofluorescence staining of insulin (green fluorescence) and TUNEL staining (red fluorescence) of pancreatic sections from $\beta W f s 1^{(-l-)}$ mice taken 5 weeks after intraperitoneal injection of AAV-control or AAV9-MANF vector ( $n=6$ each group). The magnification is $\times 10$ for each image, and $\times 40$ for the right upper images. b Quantification of Ki67-positive $\beta$ cells in AAV-control or AAV9MANF injected $\beta W f s 1^{(--)}$mice (AAV-control, $n=5$; AAV9-MANF, $n=6$; $\left.{ }^{*} P<0.05\right)$. c Quantification of $\beta$ cell mass in AAV-control or AAV9-MANF injected $\beta W f_{s} 1^{(-)}$mice $(n=6$ in each group, not significant).

\section{Discussion}

Wolfram syndrome is characterized by juvenile-onset diabetes, optic nerve atrophy and, neurodegeneration due to ER stress-mediated cell death $[6,28]$, and has been established as a prototype of ER stress disease $[8,9,11-14$, $21,29]$. Since there is no treatment that can stop or even slow the progression of this syndrome currently, developing the novel treatment has been an urgent task.

Increasing evidence indicates that MANF possesses regenerative and cytoprotective effects. In the mouse pancreas, MANF overexpression was found to induce the proliferation of pancreatic $\beta$ cells [20]. Systematic MANF overexpression or recombinant MANF peptide delivery protects the liver of old mice from inflammation and hepatocyte apoptosis [30]. Notably, recombinant human MANF peptide protects human $\beta$ cells from cytokineinduced ER stress and cell death, and induces $\beta$ cells proliferation [31]. In this study, we show that MANF treatment activates the proliferation of $\beta$ cells in human islets and prevents ER stress-mediated $\beta$ cell death and enhances $\beta$ cell proliferation in cell and mouse models of Wolfram syndrome. These results broaden the possibility of developing the new treatments for Wolfram syndrome using adeno-associated virus expressing MANF or recombinant MANF peptide. To elucidate the efficacy of MANF treatment, further experiments using the other Wolfram syndrome model mice, or $\beta$ cells which are differentiated from Wolfram syndrome patient-derived iPSCs would be required [12]. On the other hand, MANF treatment did not change insulin secretion and insulin content in INS-1 832/ 13 cells. These results are in line with the previous report using EndoC- $\beta \mathrm{H} 1$ cells [31]. Moreover, even though MANF overexpression activated the $\beta W f_{s} I^{(-/-)}$mice $\beta$ cell proliferation, the $\beta$ cell mass of these mice was not changed. A longer overexpression might be needed to study the effect of MANF on the $\beta$ cell mass.

MANF was originally isolated from astrocytes as a novel neurotrophic factor [15]. It has been reported that MANF regulates the NF-kB signaling pathway, which is considered to be activated through their receptors [31, 32]. However, receptors for MANF have not been identified. Further studies are required to identify these receptors and their signaling pathway in order to develop treatments based on small molecules that act as MANF receptor agonists.

Our results are also relevant to other diseases related to ER stress. Genetic, clinical, and experimental evidence indicates that ER stress-mediated cell death is an important pathogenic component in human chronic disorders, including type 1 and type 2 diabetes, retinal degeneration, Parkinson's disease, amyotrophic lateral sclerosis, inflammatory bowel disease, and multiple sclerosis [3, 33-39]. It has been reported that plasma MANF protein levels decline with age in flies, mice, and human [30]. In contrast, circulating MANF levels are known to increase in children with type 1 diabetes as compared with control subjects [40]. ER stress in $\beta$ cells has been linked to autoimmunity and cytokine-mediated $\beta$ cell death during the onset and progression of type 1 diabetes [41-47]. Thus, increased MANF levels in patients with type 1 diabetes may be an adaptive response to ER stress in $\beta$ cells. MANF mutations have been reported in a patient with type 2 diabetes [48]. In such disorders, MANF-based therapy may suppress ER stressmediated cell death and delay the progression of the disease.

Collectively, our results provide a rationale for identifying signaling molecules regulated by MANF, including its receptor, so that we may develop novel regenerative therapy for ER stress-related disorders, including diabetes, retinal degeneration, and Wolfram syndrome.

Acknowledgements This work was partly supported by grants from Ono Pharmaceutical Co Ltd, the National Institute of Diabetes Digestive and Kidney Diseases (NIDDK) of the National Institutes of Health (NIH) (DK112921 and DK020579), the National Center for Advancing Translational Sciences (NCATS) of the NIH (TR002065 and TR000448) and philanthropic supports from the Silberman Fund, the Ellie White Foundation for the Rare Genetic Disorders, the Snow Foundation, the Unravel Wolfram Syndrome Fund, the Stowe Fund, the Eye Hope Foundation, the Feiock Fund, the Team Alejandro, and the Team Ian to FU. Research reported in this publication was also supported by the Washington University Institute of Clinical and Translational Sciences grant UL1TR002345 from the NCATS of the $\mathrm{NIH}$ and the Washington University Diabetes Research Center supported by the NIDDK of the NIH. The content is solely the responsibility of the authors and does not necessarily represent the official view of the NIH. SM was supported by Manpei Suzuki Diabetes Foundation and JSPS Overseas Research Fellowships. DA was supported by the NIH training grant (F30DK111070). The authors thank all the members of the Washington University Wolfram Syndrome Study and Research Clinic for their support (https://wolframsyndrome. dom.wustl.edu) and all the participants in the Wolfram syndrome 
International Registry and Clinical Study, Research Clinic, and Clinical Trials for their time and efforts.

Author contributions JM, SM, and FU participated in study conception and design. JM, SM, TY, SL, KK, DA, and CMB participated in data acquisition. JM, SM, SL, KK, DA, and FU participated in data analysis and interpretation. JM, SM, CMB, and FU participated in manuscript writing.

\section{Compliance with ethical standards}

Conflict of interest FU and KK are inventors of US Patent 9,891,231 B2 entitled "SOLUBLE MANF IN PANCREATIC BETA CELL DISORDERS." FU and SL are inventors of US 10,441,574, B2 entitled "TREATMENT FOR WOLFRAM SYNDROME AND OTHER ER STRESS DISORDERS." FU received research funding from Eli Lilly, Ono Pharmaceuticals, and Amarantus BioScience for the development of MANF-based regenerative therapy for Wolfram syndrome, optic nerve atrophy, and diabetes. FU received chemical compounds from Amylyx Pharmaceuticals, Mitochon Pharmaceuticals, Aetas Pharma, and National Center for Advancing Translational Sciences for the development of small molecule-based therapies for ER stress-related disorders, including Wolfram syndrome. The other authors declare no conflict of interest.

Publisher's note Springer Nature remains neutral with regard to jurisdictional claims in published maps and institutional affiliations.

Open Access This article is licensed under a Creative Commons Attribution 4.0 International License, which permits use, sharing, adaptation, distribution and reproduction in any medium or format, as long as you give appropriate credit to the original author(s) and the source, provide a link to the Creative Commons license, and indicate if changes were made. The images or other third party material in this article are included in the article's Creative Commons license, unless indicated otherwise in a credit line to the material. If material is not included in the article's Creative Commons license and your intended use is not permitted by statutory regulation or exceeds the permitted use, you will need to obtain permission directly from the copyright holder. To view a copy of this license, visit http://creativecommons. org/licenses/by/4.0/.

\section{References}

1. Fonseca SG, Gromada J, Urano F. Endoplasmic reticulum stress and pancreatic beta-cell death. Trends Endocrinol Metab. 2011;22:266-74.

2. Walter P, Ron D. The unfolded protein response: from stress pathway to homeostatic regulation. Science. 2011;334:1081-6.

3. Wang S, Kaufman RJ. The impact of the unfolded protein response on human disease. J Cell Biol. 2012;197:857-67.

4. Hetz C, Mollereau B. Disturbance of endoplasmic reticulum proteostasis in neurodegenerative diseases. Nat Rev Neurosci. 2014;15:233-49.

5. Mollereau B, Rzechorzek NM, Roussel BD, Sedru M, Van den Brink DM, Bailly-Maitre B, et al. Adaptive preconditioning in neurological diseases-therapeutic insights from proteostatic perturbations. Brain Res. 2016. https://doi.org/10.1016/j.brainres. 2016.02.033.

6. Barrett TG, Bundey SE, Macleod AF. Neurodegeneration and diabetes: UK nationwide study of Wolfram (DIDMOAD) syndrome. Lancet. 1995;346:1458-63.

7. Urano F. Wolfram syndrome: diagnosis, management, and treatment. Curr Diab Rep. 2016;16:6.
8. Fonseca SG, Fukuma M, Lipson KL, Nguyen LX, Allen JR, Oka $\mathrm{Y}$, et al. WFS1 is a novel component of the unfolded protein response and maintains homeostasis of the endoplasmic reticulum in pancreatic beta-cells. J Biol Chem. 2005;280:39609-15.

9. Fonseca SG, Ishigaki S, Oslowski CM, Lu S, Lipson KL, Ghosh $\mathrm{R}$, et al. Wolfram syndrome 1 gene negatively regulates ER stress signaling in rodent and human cells. J Clin Investig. 2010;120:744-55.

10. Lu S, Kanekura K, Hara T, Mahadevan J, Spears LD, Oslowski $\mathrm{CM}$, et al. A calcium-dependent protease as a potential therapeutic target for Wolfram syndrome. Proc Natl Acad Sci USA. 2014;111: E5292-301.

11. Urano F. Diabetes: targeting endoplasmic reticulum to combat juvenile diabetes. Nat Rev Endocrinol. 2014;10:129-30.

12. Urano F. Wolfram syndrome iPS cells: the first human cell model of endoplasmic reticulum disease. Diabetes. 2014;63:844-6.

13. Abreu D, Asada R, Revilla JMP, Lavagnino Z, Kries K, Piston DW, et al. Wolfram syndrome 1 gene regulates pathways maintaining beta-cell health and survival. Lab Investig. 2020. https:// doi.org/10.1038/s41374-020-0408-5.

14. Abreu D, Urano F. Current landscape of treatments for Wolfram syndrome. Trends Pharmacol Sci. 2019;40:711-4.

15. Petrova P, Raibekas A, Pevsner J, Vigo N, Anafi M, Moore MK, et al. MANF: a new mesencephalic, astrocyte-derived neurotrophic factor with selectivity for dopaminergic neurons. J Mol Neurosci. 2003;20:173-88.

16. Mizobuchi N, Hoseki J, Kubota H, Toyokuni S, Nozaki J, Naitoh $\mathrm{M}$, et al. ARMET is a soluble ER protein induced by the unfolded protein response via ERSE-II element. Cell Struct Funct. 2007;32:41-50.

17. Glembotski CC, Thuerauf DJ, Huang C, Vekich JA, Gottlieb RA, Doroudgar S. Mesencephalic astrocyte-derived neurotrophic factor protects the heart from ischemic damage and is selectively secreted upon sarco/endoplasmic reticulum calcium depletion. J Biol Chem. 2012;287:25893-904.

18. Henderson MJ, Richie CT, Airavaara M, Wang Y, Harvey BK. Mesencephalic astrocyte-derived neurotrophic factor (MANF) secretion and cell surface binding are modulated by KDEL receptors. J Biol Chem. 2013;288:4209-25.

19. Yu YQ, Liu LC, Wang FC, Liang Y, Cha DQ, Zhang JJ, et al. Induction profile of MANF/ARMET by cerebral ischemia and its implication for neuron protection. J Cereb Blood Flow Metab. 2010;30:79-91.

20. Lindahl M, Danilova T, Palm E, Lindholm P, Voikar V, Hakonen $\mathrm{E}$, et al. MANF is indispensable for the proliferation and survival of pancreatic beta cells. Cell Rep. 2014;7:366-75.

21. Riggs AC, Bernal-Mizrachi E, Ohsugi M, Wasson J, Fatrai S, Welling C, et al. Mice conditionally lacking the Wolfram gene in pancreatic islet beta cells exhibit diabetes as a result of enhanced endoplasmic reticulum stress and apoptosis. Diabetologia. 2005;48:2313-21.

22. Hara T, Mahadevan J, Kanekura K, Hara M, Lu S, Urano F. Calcium efflux from the endoplasmic reticulum leads to beta-cell death. Endocrinology. 2014;155:758-68.

23. Oh-Hashi K, Tanaka K, Koga H, Hirata Y, Kiuchi K. Intracellular trafficking and secretion of mouse mesencephalic astrocytederived neurotrophic factor. Mol Cell Biochem. 2012;363:35-41.

24. Zinszner H, Kuroda M, Wang X, Batchvarova N, Lightfoot RT, Remotti $\mathrm{H}$, et al. CHOP is implicated in programmed cell death in response to impaired function of the endoplasmic reticulum. Genes Dev. 1998;12:982-95.

25. Marciniak SJ, Yun CY, Oyadomari S, Novoa I, Zhang Y, Jungreis $\mathrm{R}$, et al. CHOP induces death by promoting protein synthesis and oxidation in the stressed endoplasmic reticulum. Genes Dev. 2004;18:3066-77. 
26. Qian B, Wang H, Men X, Zhang W, Cai H, Xu S, et al. TRIB3 [corrected] is implicated in glucotoxicity- and endoplasmic reticulum-stress-induced [corrected] beta-cell apoptosis. J Endocrinol. 2008;199:407-16.

27. Kanekura K, Ma X, Murphy JT, Zhu LJ, Diwan A, Urano F. IRE1 prevents endoplasmic reticulum membrane permeabilization and cell death under pathological conditions. Sci Signal. 2015;8:ra62.

28. Barrett TG, Bundey SE. Wolfram (DIDMOAD) syndrome. J Med Genet. 1997;34:838-41.

29. Ishihara H, Takeda S, Tamura A, Takahashi R, Yamaguchi S, Takei D, et al. Disruption of the WFS1 gene in mice causes progressive beta-cell loss and impaired stimulus-secretion coupling in insulin secretion. Hum Mol Genet. 2004;13:1159-70.

30. Sousa-Victor P, Neves J, Cedron-Craft W, Ventura PB, Liao CY, Riley RR, et al. MANF regulates metabolic and immune homeostasis in ageing and protects against liver damage. Nat Metab. 2019;1:276-90.

31. Hakonen E, Chandra V, Fogarty CL, Yu NY, Ustinov J, Katayama $S$, et al. MANF protects human pancreatic beta cells against stress-induced cell death. Diabetologia. 2018. https://doi. org/10.1007/s00125-018-4687-y.

32. Chen L, Feng L, Wang X, Du J, Chen Y, Yang W, et al. Mesencephalic astrocyte-derived neurotrophic factor is involved in inflammation by negatively regulating the NF-kappaB pathway. Sci Rep. 2015;5:8133.

33. Lindholm D, Wootz H, Korhonen L. ER stress and neurodegenerative diseases. Cell Death Differ. 2006;13:385-92.

34. Lin W, Bailey SL, Ho H, Harding HP, Ron D, Miller SD, et al. The integrated stress response prevents demyelination by protecting oligodendrocytes against immune-mediated damage. J Clin Investig. 2007;117:448-56.

35. Getts MT, Getts DR, Kohm AP, Miller SD. Endoplasmic reticulum stress response as a potential therapeutic target in multiple sclerosis. Therapy. 2008;5:631-40.

36. Kaser A, Lee AH, Franke A, Glickman JN, Zeissig S, Tilg H, et al. XBP1 links ER stress to intestinal inflammation and confers genetic risk for human inflammatory bowel disease. Cell. 2008;134:743-56.

37. Fonseca SG, Burcin M, Gromada J, Urano F. Endoplasmic reticulum stress in beta-cells and development of diabetes. Curr Opin Pharmacol. 2009;9:763-70.
38. Kaufman RJ. Beta-cell failure, stress, and type 2 diabetes. N Engl J Med. 2011;365:1931-3.

39. Kroeger H, Chiang WC, Felden J, Nguyen A, Lin JH. ER stress and unfolded protein response in ocular health and disease. FEBS J. 2019;286:399-412.

40. Galli E, Harkonen T, Sainio MT, Ustav M, Toots U, Urtti A, et al. Increased circulating concentrations of mesencephalic astrocytederived neurotrophic factor in children with type 1 diabetes. Sci Rep. 2016;6:29058.

41. Cardozo AK, Ortis F, Storling J, Feng YM, Rasschaert J, Tonnesen $\mathrm{M}$, et al. Cytokines downregulate the sarcoendoplasmic reticulum pump $\mathrm{Ca} 2+$ ATPase $2 \mathrm{~b}$ and deplete endoplasmic reticulum $\mathrm{Ca} 2+$, leading to induction of endoplasmic reticulum stress in pancreatic beta-cells. Diabetes. 2005;54:452-61.

42. O'Sullivan-Murphy B, Urano F. ER stress as a trigger for beta-cell dysfunction and autoimmunity in type 1 diabetes. Diabetes. 2012;61:780-1.

43. Oslowski CM, Hara T, O’Sullivan-Murphy B, Kanekura K, Lu S, Hara M, et al. Thioredoxin-interacting protein mediates ER stressinduced beta cell death through initiation of the inflammasome. Cell Metab. 2012;16:265-73.

44. Tersey SA, Nishiki Y, Templin AT, Cabrera SM, Stull ND, Colvin SC, et al. Islet beta-cell endoplasmic reticulum stress precedes the onset of type 1 diabetes in the nonobese diabetic mouse model. Diabetes. 2012;61:818-27.

45. Yang C, Diiorio P, Jurczyk A, O'Sullivan-Murphy B, Urano F, Bortell R. Pathological endoplasmic reticulum stress mediated by the IRE1 pathway contributes to pre-insulitic beta cell apoptosis in a virus-induced rat model of type 1 diabetes. Diabetologia. 2013;56:2638-46.

46. Unanue ER, Urano F. Endoplasmic reticulum: an interface between the immune system and metabolism. Diabetes. 2014;63:48-49.

47. Vomund AN, Zinselmeyer BH, Hughes J, Calderon B, Valderrama $\mathrm{C}$, Ferris ST, et al. Beta cells transfer vesicles containing insulin to phagocytes for presentation to T cells. Proc Natl Acad Sci USA. 2015;112:E5496-5502.

48. Yavarna T, Al-Dewik N, Al-Mureikhi M, Ali R, Al-Mesaifri F, Mahmoud L, et al. High diagnostic yield of clinical exome sequencing in Middle Eastern patients with Mendelian disorders. Hum Genet. 2015;134:967-80. 